Problems of Nutrition in South Africa.

Race Relations, the official quarterly journal of the South African Institute of Race Relations, has devoted a number entirely to the problem of nutrition of the South African peoples, White, Black and Coloured. ${ }^{I}$ It brings to mind the similar number of Africa published in 1936 (vol. ix, no. 2), which concentrated also on diet questions, dealing in that case with the food and food-supplies of the Native peoples of Africa as a whole. Both these special numbers are very welcome, not only for the information they give on a subject on which little has so far been published, but as a sign of the rapidly growing interest in nutrition in official circles and among the members of the general public itself.

The present volume will be particularly valuable to the interested laymanfirst because it consists of a series of short articles written in a form which makes them easily comprehensible to those who have little specialist training, and secondly because it envisages the problem of nutrition from such a wide point of view. The contributors include medical officers, bio-chemists, agricultural authorities, economists and politicians, and each discusses the food supply of the African peoples as a problem of general social policy for the whole country. They do more; they treat the nutrition of the Black population as of the same importance as that of the White, assume the physiological needs of the Native to be similar to those of the European even though their present eating habits may differ, and envisage long-time policies which should benefit Black, Coloured and White alike. This gives the volume an important educational value in a society which must be recognized more and more as an organized caste system in which it is only too easy to assume that Natives need less to eat than Coloured and Coloured less than White, and even medical authorities fail sometimes to realize the dangers of a grossly under-nourished Black population.

The first section of the journal describes present conditions as regards diet in the case of Europeans, Coloured and Black. Dr. F. W. Fox contributes an interesting article on the food of Natives in the rural areasparticularly in the Transkei-while Mrs. Ellen Hellmann describes the diet of urban Africans in the Johannesburg locations. There are a number of extremely valuable charts. These include European and Native budgets from several urban areas, and in particular Dr. C. C. P. Anning's interesting comparison of the amount of money spent on food by Europeans and Natives respectively in Benoni, one of the Rand municipalities. There is also a table of the diet scales at present used in a number of non-European institutions, hospitals, schools, \&c., as well as Dr. A. J. Orenstein's brief account of the Rand Mine scales. Indians are not dealt with for want of

${ }^{1}$ Race Relations, vol. vi, no. I. South African Institute of Race Relations, University of the Witwatersrand, Johannesburg. Price is. 
adequate information, but Dr. J. P. de Villiers describes conditions among Cape Coloured peoples and Dr. Karl Bremer talks of the nutrition, or rather malnutrition, of Europeans in rural areas.

The second half of the number deals with the future. Here Dr. D.G. Haylett makes an important contribution by analysing the food resources of the Union as a whole under various heads-animal and dairy produce, produce of plant origin, \&c. These figures he compares with the estimated calorie needs of the population per head. To all the writers in this section economic and social factors are the chief determinants of malnutrition, and the disastrous effects of low wages, colout-bar legislation, preventing the use of the Union's potential resources in man-power, and the Government's policy of subsidizing the export of food crops are facts deplored in each article.

As a whole the volume gives two main impressions. The first is the seriousness of the Native food question, either in the reserves where the man-power has been reduced by half and the soil is wasted by erosion, or in the towns where low wages drive the people to live on an inadequate diet of bread and tea; an extreme shortage of special constituents-i.e. milk, fats and fresh vegetables-being marked in both cases. Second, it is stressed that the country as a whole is poor, and hence the vital importance of a forward long-time policy concentrating on increased production of foodstuffs, restriction rather than encouragement of their export and a raised purchasing-power for the poorest section of the community. Few clinical surveys of the results of malnutrition are referred to, but the data on this aspect is only now accumulating in South Africa. The importance and diffculties of research into the nutrition of rural Natives is also hardly touched on, and here again the work has been little more than begun. But we must be grateful for useful material recorded in a handy form, and hope continuously for more. (Contributed by Dr. Audrex I. Richards.)

\section{The Learning Ability of the South African Native.}

THE South African Council for Educational and Social Research has recently published a pamphlet on The Learning Ability of the South African Native Compared with that of the European, by Dr. J. A. Jansen van Rensburg of the University of Stellenbosch. It ends with this momentous declaration: 'It would seem from the foregoing investigation that the South African Native has not the learning ability to be able to compete on equal terms with the average European, except in tasks of an extremely simple nature.' This weighty conclusion is based on the results of four ' learning' tests applied to I8I European pupils 14-15 years of age and 398 Xhosa school children of as near that age-group as could be estimated. The children were tested individually, the same test being repeated successively until the limit of improvement was reached. Dr. van Rensburg stresses the difficulty of 